\title{
Clinicopathological characteristics and optimal management for esophagogastric junctional cancer; a single center retrospective cohort study
}

Hiroaki Ito*, Haruhiro Inoue, Noriko Odaka, Hitoshi Satodate, Michitaka Suzuki, Shumpei Mukai, Yusuke Takehara, Hiroyuki Kida and Shin-ei Kudo

\begin{abstract}
Background: Esophagogastric junctional (EGJ) cancer occurs in the mucosa near the esophagogastric junction, and has characteristics of both esophageal and gastric malignancies; its optimal treatment strategy is controversial.

Methods: We conducted a single-center retrospective cohort study of the patients who underwent curative surgery with lymphadenectomy for EGJ cancer. Tumor specimens were categorized by histology and location into four types - centered in the esophagus $<5 \mathrm{~cm}$ from EGJ (type E), which were subtyped as (i) squamous-cell carcinoma (SQ) or (ii) adenocarcinoma (AD); (iii) any histological tumor centered in the stomach $<5 \mathrm{~cm}$ from EGJ, with EGJ invasion (type Ge); (iv) any histological tumor centered in the stomach $<5 \mathrm{~cm}$ from EGJ, without EGJ invasion (type G) —and classified by TNM system; these were compared to patients' clinicopathological characteristics and survival outcomes.

Results: A total of 92 EGJ cancer patients were studied. Median follow-up of surviving patients was 35.5 months. Tumors were categorized as 12 type E (SQ), 6 type E (AD), 27 type Ge and 47 type G; of these 7 (58.3\%), 3 (50\%), 19 (70.4\%) and 14 (29.8\%) and 23 patients, respectively, had lymph node metastases. No patients with type E (AD) and Ge tumors had cervical lymph node metastasis; those with type $\mathrm{G}$ tumors had no nodal metastasis at cervical and mediastinal lymph nodes. Multivariate analysis showed that type $E(A D)$ tumor was an independent prognostic factor.
\end{abstract}

Conclusions: We should distinguish type Ge tumor from type E (AD) tumor because of the clinicopathological and prognostic differentiation. Extended gastrectomy with or without lower esophagectomy according to tumor location and lower mediastinal and abdominal lymphadenectomy are recommended for EGJ cancer.

Trial registration: University Hospital Medical Information Network in Japan, UMIN000008596.

Keywords: Esophagogastric junctional cancer, Esophageal cancer, Gastric cancer, Lymph node metastasis

\section{Background}

Gastric and esophageal cancers are, respectively, the fourth and eighth most common cancers in the world, and the second and sixth most common causes of cancer-related death, affecting approximately 736,000 and 406,000 people in 2008 [1]. Esophagogastric junctional cancer (EGJC), which is increasing in Western countries, is a tumor occurring at the mucosa between the lower esophagus and cardia, and has clinicopathological

\footnotetext{
* Correspondence: h.ito@med.showa-u.ac.jp

Digestive Disease Center, Showa University Northern Yokohama Hospital, 35-1 Chigasakichuo Tsuzuki-ku, Yokohama 224-8503, Japan
}

characteristics of both esophageal and gastric malignancies $[2,3]$.

Siewert classification is widely used to categorize EG) adenocarcinoma $[4,5]$. Siewert defines adenocarcinoma of the distal esophagus, such as that from specialized esophageal metaplasia (e.g., Barrett's esophagus) as type I; cardiac carcinoma, from the cardia epithelium or within $1 \mathrm{~cm}$ (along the esophagus) or $2 \mathrm{~cm}$ (in the stomach) from the EGJ as type II; and subcardial gastric carcinoma with epicenter in the proximal $5 \mathrm{~cm}$ of the stomach, which infiltrates the EGJ and distal esophagus, as type III. Because the Siewert type I tumor is located

\section{Biomed Central}

(c) 2013 Ito et al.; licensee BioMed Central Ltd. This is an Open Access article distributed under the terms of the Creative Commons Attribution License (http://creativecommons.org/licenses/by/2.0), which permits unrestricted use, distribution, and reproduction in any medium, provided the original work is properly cited. 


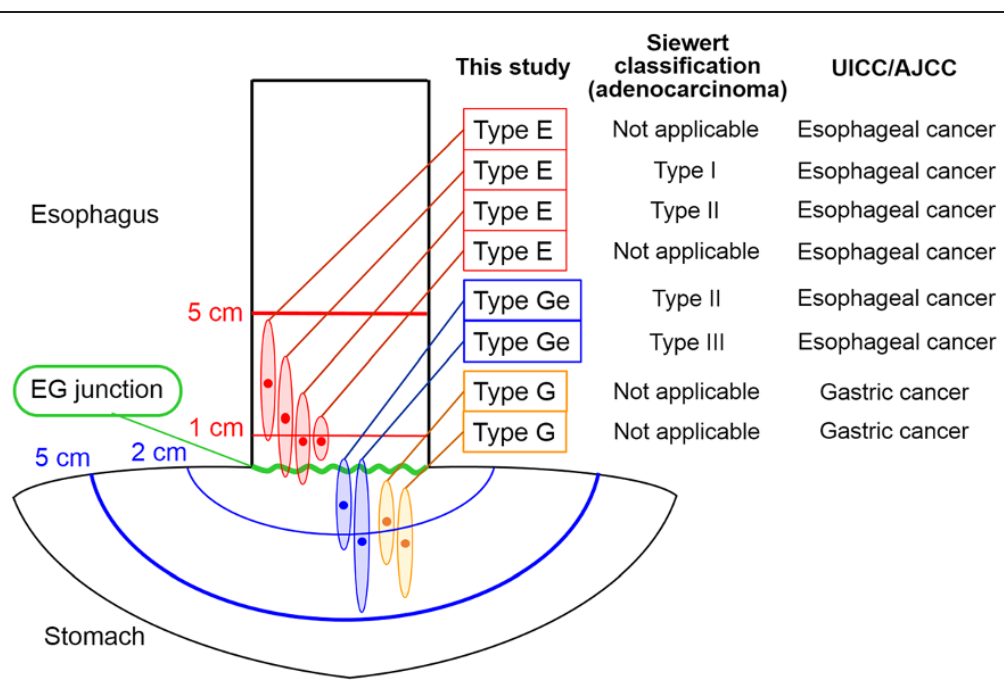

Figure 1 Tumor classification. We categorized tumors near the EGJ into four types according to its location and main histological type. Categorization criteria were: (i) squamous-cell carcinoma with epicenter in the esophagus within $5 \mathrm{~cm}$ from EGJ (type E (SQ)); (ii) adenocarcinoma with epicenter in the esophagus within $5 \mathrm{~cm}$ from EGJ (type E (AD)); (iii) any histological tumor with epicenter in the stomach within $5 \mathrm{~cm}$ from EGJ, with EGJ invasion (type Ge); (iv) any histological tumor with epicenter in the stomach within $5 \mathrm{~cm}$ from EGJ, without EGJ invasion (type G). Type E (SQ), E (AD) and Ge tumors were categorized as esophageal cancer; type G tumor was categorized as gastric cancer by the American Joint Committee on Cancer/International Union Against Cancer (AJCC/UICC) Cancer Staging Manual. Siewert type I and III tumors were categorized as type E (AD) and Ge tumors, and Siewert type II tumor was categorized as type E (AD) or Ge tumor in this study.

in the lower esophagus, it can be treated as lower esophageal cancer; whereas type III tumor has similar clinicopathological characteristics to cardiac cancer because of its location. However, Siewert type II tumor is a metastatic threat to both thoracic and abdominal areas, as it crosses the EGJ. Subtotal esophagectomy offers only a limited benefit and should not be performed for type II cancer. The TNM staging system according to the seventh edition of the American Joint Committee on Cancer/International Union Against Cancer (AJCC/UICC) Cancer Staging Manual defined EGJC, including of squamous-cell carcinoma and adenocarcinoma centered in the esophagus within $5 \mathrm{~cm}$, and in the proximal $5 \mathrm{~cm}$ of the stomach with crossing the EGJ $[6,7]$. AJCC/UICC also categorizes any cardiac cancer without EGJ invasion as gastric cancer regardless of its location. Different staging systems are applied to esophageal squamous-cell carcinoma and esophageal adenocarcinoma.

Surgery is effective treatment for resectable esophageal $[8,9]$ and gastric cancer [10-12]. However, as esophagectomy is generally more invasive than gastrectomy [13], we should be careful in treating EGJC with esophagectomy.

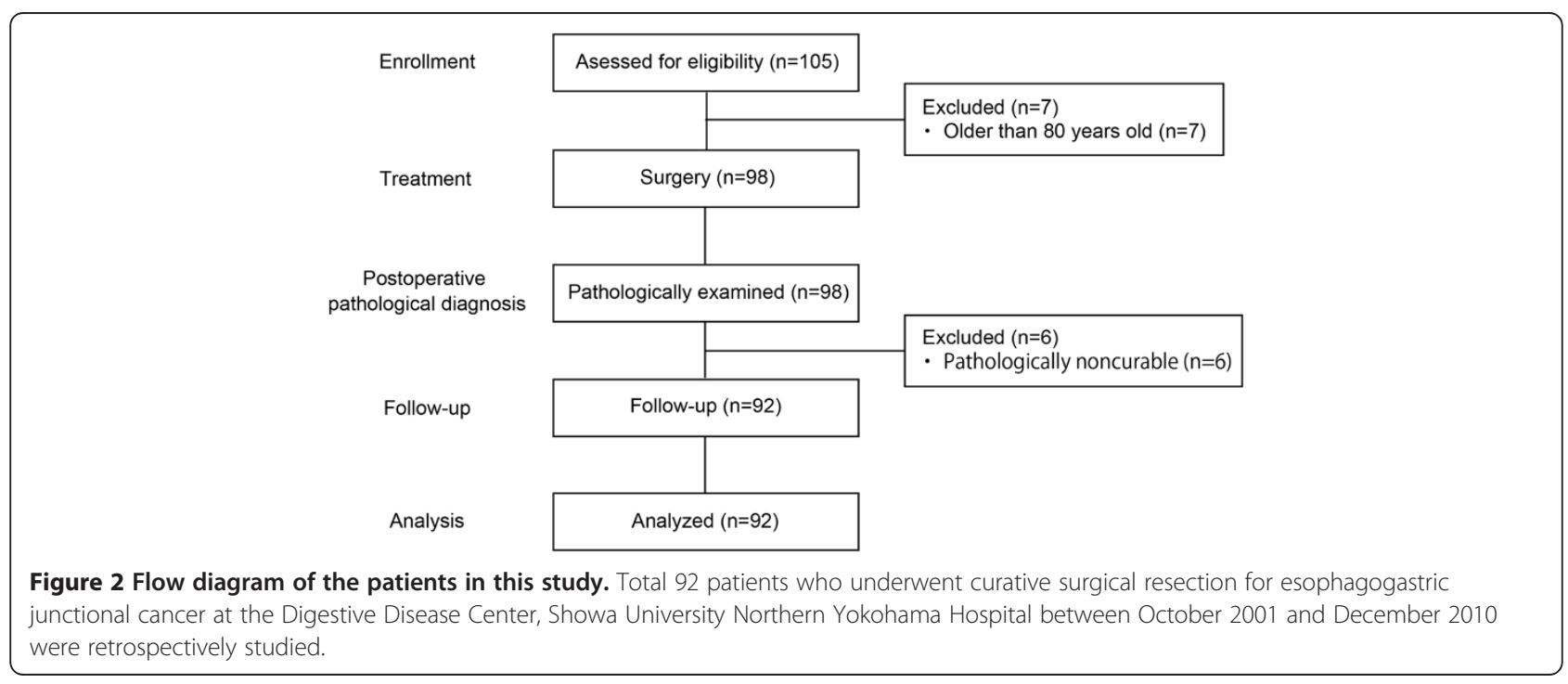


Table 1 Patient characteristics $(\mathbf{n}=92)$

\begin{tabular}{|c|c|c|}
\hline & Variables & \\
\hline Age (year, mean $\pm S D$ ) & & $65.9 \pm 9.4$ \\
\hline \multirow[t]{2}{*}{ Sex } & Male & $72(78.3 \%)$ \\
\hline & Female & $20(21.7 \%)$ \\
\hline \multirow[t]{4}{*}{ Siewert classification } & Type I adenocarcinoma & $2(2.2 \%)$ \\
\hline & Type II adenocarcinoma & $16(17.4 \%)$ \\
\hline & Type III adenocarcinoma & $11(12.0 \%)$ \\
\hline & Not applicable & $63(68.5 \%)$ \\
\hline \multirow[t]{6}{*}{ Macro type } & Type 0 & $36(39.1 \%)$ \\
\hline & Type 1 & $4(4.3 \%)$ \\
\hline & Type 2 & $26(28.3 \%)$ \\
\hline & Type 3 & $21(22.8 \%)$ \\
\hline & Type 4 & $1(1.1 \%)$ \\
\hline & Type 5 & $4(4.3 \%)$ \\
\hline \multirow[t]{2}{*}{ Preoperative chemotherapy } & No & $79(85.9 \%)$ \\
\hline & Yes & $13(14.1 \%)$ \\
\hline \multirow[t]{3}{*}{ Extent of surgical resection } & Subtotal esophagectomy with partial gastrectomy & $14(15.2 \%)$ \\
\hline & Proximal gastrectomy with partial esophagectomy & $30(32.6 \%)$ \\
\hline & Total gastrectomy with partial esophagectomy & $48(52.2 \%)$ \\
\hline \multirow[t]{4}{*}{ Extent of lymph node dissection } & Abdominal, mediastinal and cervical & $11(12.0 \%)$ \\
\hline & Abdominal and mediastinal & $9(9.8 \%)$ \\
\hline & Abdominal and lower mediastinal $^{\dagger}$ & $27(29.3 \%)$ \\
\hline & Abdominal & $45(48.9 \%)$ \\
\hline Pathological tumor size $(\mathrm{mm}$, mean $\pm \mathrm{SD})$ & & $46.1 \pm 23.7$ \\
\hline \multirow[t]{2}{*}{ Main histologic type } & Adenocarcinoma & $79(85.9 \%)$ \\
\hline & Squamous-cell carcinoma & $13(14.1 \%)$ \\
\hline \multirow[t]{2}{*}{ Lymphatic invasion } & LO & $32(34.8 \%)$ \\
\hline & L1 & $60(65.2 \%)$ \\
\hline \multirow[t]{2}{*}{ Venous invasion } & V0 & $32(34.8 \%)$ \\
\hline & $\mathrm{V} 1-2$ & $60(65.2 \%)$ \\
\hline \multirow[t]{4}{*}{ Pathological depth of tumor invasion } & pT1 & $33(35.9 \%)$ \\
\hline & pT2 & $11(12.0 \%)$ \\
\hline & pT3 & $35(38.0 \%)$ \\
\hline & pT4 & $13(14.1 \%)$ \\
\hline \multirow[t]{4}{*}{ Lymph node metastasis } & pNO & $47(51.1 \%)$ \\
\hline & pN1 & $19(20.7 \%)$ \\
\hline & pN2 & $14(15.2 \%)$ \\
\hline & pN3 & $12(13.0 \%)$ \\
\hline \multirow[t]{2}{*}{ Distant metastasis } & $\mathrm{pMO}$ & $72(78.3 \%)$ \\
\hline & $\mathrm{pM} 1$ & $20(21.7 \%)$ \\
\hline \multirow[t]{4}{*}{ TNM stage } & pStage I & $36(39.1 \%)$ \\
\hline & pStage ॥ & $19(20.7 \%)$ \\
\hline & pStage III & $17(18.5 \%)$ \\
\hline & pStage IV & $20(21.7 \%)$ \\
\hline
\end{tabular}


Table 1 Patient characteristics $(\mathbf{n}=\mathbf{9 2})$ (Continued)

\begin{tabular}{lll}
\hline Adjuvant chemotherapy & No & $43(46.7 \%)$ \\
& Yes & $49(53.3 \%)$
\end{tabular}

Including lower thoracic paraesophageal, diaphragmatic and posterior mediastinal lymph node.

We studied clinicopathological characteristics of patients with EGJC to investigate its optimal management.

\section{Methods}

\section{Study design}

We performed a single center, retrospective cohort study. We studied patients who underwent curative surgery for EGJC, including lymph node dissection, at the Digestive Disease Center, Showa University Northern Yokohama Hospital, between October 2001 and December 2010. Clinicopathological data and prognosis were taken from medical records.

\section{Patients}

We studied patients with cancer in the lower esophagus and cardia. Inclusion criteria were: (i) presence of histologically proven carcinoma centered within the lower $5 \mathrm{~cm}$ of the esophagus and the upper $5 \mathrm{~cm}$ of the stomach; (ii) clinically solitary tumors; (iii) no prior endoscopic resection or surgical treatment; and (iv) patient aged 2080 years. The exclusion criteria were: (i) presence of severe organ dysfunction; (ii) presence of metachronous and synchronous malignancy; and (iii) presence of pathological non-curative findings.

All patient data were approved for use by the institutional review board of Showa University Northern Yokohama Hospital. This study was registered with the University Hospital Medical Information Network in Japan (No. UMIN000008596).

\section{Classification}

Although Siewert classification is one of the most widely used criteria for EGJC, it is generally used for only adenocarcinoma. EGJC, including squamous cell carcinoma, has been defined by the seventh edition of AJCC/ UICC TNM Cancer Staging Manual. However, it does not cover all of the cancer near the EGJ-for example a localized gastric adenocarcinoma with centered in the stomach within $5 \mathrm{~cm}$ from EGJ. Thus, we categorized tumors near the EGJ into four types, according to location and main histological type (Figure 1). Categorization criteria were: (i) squamous-cell carcinoma centered in the esophagus within $5 \mathrm{~cm}$ from EGJ (type E (SQ)); (ii) adenocarcinoma centered in the esophagus within $5 \mathrm{~cm}$ from EGJ (type E (AD)); (iii) any histological tumor centered in the stomach within $5 \mathrm{~cm}$ from EGJ, with EGJ invasion (type Ge); (iv) any histological tumor centered in the stomach within $5 \mathrm{~cm}$ from EGJ, without EGJ invasion (type G). All disease was pathologically staged using the seventh edition of AJCC/UICC TNM Cancer Staging Manual [6,7]. Thus, types E and Ge tumors were staged as esophageal cancer, and type $G$ tumor was staged as gastric cancer.

\section{Statistical analysis}

Statistical analysis was performed using JMP 9.0.3 (SAS Institute, Cary, USA). We used Fisher's exact test and Pearson's chi-squared test to compare the characteristics of the patients and pathological findings. The nonparametric Kruskal-Wallis test was used to assess differences among patients' age groups, number of dissected lymph nodes and pathological tumor size. Kaplan-Meier curves of estimated overall survival were generated and compared, using a 2-sided log-rank test. To investigate prognostic factors, Cox proportional hazard analysis was used. Multivariate analysis included tumor types and variables with $P<0.10$ in univariate analysis. $P<0.05$ was considered statistically significant.

\section{Results}

\section{Patient characteristics}

A total of 92 patients were included in this study (Figure 2). Median follow-up of surviving patients was 35.5 months. Patients' characteristics are summarized in Table 1. Approximately $80 \%$ of them were men; their average age was 65.9 years (range: $35-80$ years). Fourteen $(15.2 \%), 30(32.6 \%)$ and $48(52.2 \%)$ patients underwent subtotal esophagectomy with partial gastrectomy, proximal gastrectomy with partial esophagectomy and total gastrectomy with partial esophagectomy, respectively. Twenty-four patients underwent splenectomy to remove involved lymph nodes at the splenic hilum. Thirteen patients $(14.1 \%)$ received preoperative chemotherapy. Histologically, $79(85.9 \%)$ and $13(14.1 \%)$ of 92 patients had tumors mainly composed with adenocarcinoma and squamous cell carcinoma. Mean pathological tumor size was $46.1 \mathrm{~mm}$. Two, 16 and 11 tumors were categorized as Siewert types I, II and III, respectively; Siewert classification was not applicable to the remaining 63 tumors. In 63 tumors which did not apply to Siewert classification, 50 and 13 tumors were mainly composed with adenocarcinoma and squamous cell carcinoma. However 15 and 48 tumors centered in the esophagus and the stomach, only one tumor had esophagogastric junctional invasion. Eighteen (19.6\%), 27 (29.3\%) and 47 (51.1\%) tumors were categorized type E, $\mathrm{G}$ and $\mathrm{Ge}$, respectively. The mean number of dissected 
Table 2 Comparison of clinicopathological characteristics

\begin{tabular}{|c|c|c|c|c|c|}
\hline Variable & Type E (SQ) $(n=12)$ & Type E (AD) $(n=6)$ & Type Ge $(n=27)$ & Type G $(n=47)$ & $P$-value \\
\hline Sex & & & & & 0.906 \\
\hline Male & 10 & 5 & 20 & 37 & \\
\hline Female & 2 & 1 & 7 & 10 & \\
\hline Age (mean $\pm S D)$ & $64.4 \pm 6.84$ & $66.3 \pm 7.97$ & $65.2 \pm 10.6$ & $66.5 \pm 9.67$ & 0.728 \\
\hline Extent of surgical resection & & & & & $<0.001^{* *}$ \\
\hline Subtotal esophagectomy with partial gastrectomy & 11 & 3 & 0 & 0 & \\
\hline Proximal gastrectomy with partial esophagectomy & 1 & 1 & 8 & 20 & \\
\hline Total gastrectomy with partial esophagectomy & 0 & 2 & 19 & 27 & \\
\hline Extent of lymph node dissection & & & & & $<0.001^{* *}$ \\
\hline Abdominal, mediastinal and cervical & 9 & 2 & 0 & 0 & \\
\hline Abdominal and mediastinal & 2 & 3 & 4 & 0 & \\
\hline Abdominal and lower mediastinal $^{\dagger}$ & 1 & 1 & 17 & 8 & \\
\hline Abdominal & 0 & 0 & 6 & 39 & \\
\hline Number of dissected lymph nodes (mean \pm SD) & $28.1 \pm 12.1$ & $28.7 \pm 18.1$ & $46.4 \pm 34.6$ & $35.3 \pm 26.8$ & 0.295 \\
\hline Pathological tumor size $(\mathrm{mm}$, mean $\pm \mathrm{SD})$ & $46.3 \pm 22.4$ & $41.5 \pm 36.4$ & $62.2 \pm 18.6$ & $37.9 \pm 20.5$ & $<0.001^{* *}$ \\
\hline Main histological type & & & & & $<0.001^{* *}$ \\
\hline Squamous cell carcinoma & 12 & 0 & 1 & 0 & \\
\hline Adenocarcinoma & 0 & 6 & 26 & 47 & \\
\hline Esophagogastric junctional invasion & & & & & $<0.001^{* *}$ \\
\hline Yes & 6 & 3 & 27 & 0 & \\
\hline No & 6 & 3 & 0 & 47 & \\
\hline Siewert classification & & & & & $<0.001^{* *}$ \\
\hline Type I & 2 & 0 & 0 & 0 & \\
\hline Type II & 1 & 0 & 15 & 0 & \\
\hline Type III & 0 & 0 & 11 & 0 & \\
\hline Not applicable & 3 & 12 & 1 & 47 & \\
\hline Depth of tumor invasion & & & & & $0.025^{*}$ \\
\hline pT1 & 3 & 3 & 4 & 23 & \\
\hline pT2 & 0 & 1 & 3 & 7 & \\
\hline pT3 & 9 & 2 & 14 & 10 & \\
\hline pT4 & 0 & 0 & 6 & 7 & \\
\hline Lymph node metastasis & & & & & $0.005^{* *}$ \\
\hline pNO & 3 & 3 & 8 & 33 & \\
\hline pN1 & 6 & 2 & 6 & 5 & \\
\hline pN2 & 2 & 1 & 5 & 6 & \\
\hline pN3 & 1 & 0 & 8 & 3 & \\
\hline Distant metastasis & & & & & $<0.001^{* *}$ \\
\hline Mo & 8 & 5 & 12 & 47 & \\
\hline M1 & 4 & 1 & 15 & 0 & \\
\hline TNM Stage & & & & & $<0.001^{* *}$ \\
\hline pStage I & 2 & 3 & 4 & 27 & \\
\hline pStage II & 2 & 0 & 6 & 11 & \\
\hline pStage III & 4 & 2 & 2 & 9 & \\
\hline pStage IV & 4 & 1 & 15 & 0 & \\
\hline
\end{tabular}

${ }^{*} \mathrm{P}<0.05,{ }^{* *} \mathrm{P}<0.01$

${ }^{+}$Including lower thoracic paraesophageal, diaphragmatic and posterior mediastinal lymph node. 
Table 3 Number of patients with positive nodes

\begin{tabular}{|c|c|c|c|c|c|}
\hline Variable & Type E (SQ) $(n=12)$ & Type E (AD) $(n=6)$ & Type Ge $(n=27)$ & Type G $(n=47)$ & $P$-value \\
\hline Overall & $7 / 12(58.3 \%)$ & $3 / 6(50.0 \%)$ & 19/27 (70.4\%) & $14 / 47(29.8 \%)$ & $0.003^{* *}$ \\
\hline \multicolumn{6}{|l|}{ Depth of tumor invasion } \\
\hline pT1 & $2 / 3(66.7 \%)$ & $0 / 3$ & $2 / 4(50.0 \%)$ & $0 / 23$ & $0.001^{* *}$ \\
\hline pT2 & - & $1 / 1(100 \%)$ & $2 / 3(66.7 \%)$ & 3/7 (42.9\%) & 0.497 \\
\hline pT3 & $5 / 9(55.6 \%)$ & $2 / 2(100.0 \%)$ & 9/14 (64.3\%) & 6/10 (60.0\%) & 0.697 \\
\hline pT4 & - & - & 6/6 (100\%) & 5/7 (71.4\%) & 0.269 \\
\hline \multicolumn{6}{|l|}{ Main histological type } \\
\hline Squamous-cell carcinoma & $7 / 12(66.7 \%)$ & - & $0 / 1$ & - & 0.462 \\
\hline Adenocarcinoma & - & $3 / 6(50.0 \%)$ & 19/26 (73.1\%) & 14/47 (29.8\%) & $0.002^{* *}$ \\
\hline \multicolumn{6}{|l|}{ Location of lymph nodet } \\
\hline Cervical LN & $2 / 9(22.2 \%)$ & $0 / 2$ & - & - & 0.655 \\
\hline Upper-middle mediastinal & $0 / 11$ & $0 / 5$ & $0 / 4$ & - & - \\
\hline Lower mediastinal $^{\ddagger}$ & $2 / 12(16.7 \%)$ & $2 / 6(33.3 \%)$ & $2 / 20(10.0 \%)$ & $0 / 8$ & 0.298 \\
\hline Perigastric LN & 6/12 (50.0\%) & $3 / 6(50.0 \%)$ & 17/27 (63.0\%) & $13 / 47$ (27.7\%) & $0.026^{*}$ \\
\hline Left paracardial & 1 & 2 & 8 & 2 & \\
\hline Right paracardial & 3 & 3 & 10 & 5 & \\
\hline Lesser curvature & 4 & 1 & 13 & 10 & \\
\hline Greater curvature & 0 & 1 & 4 & 1 & \\
\hline Suprapyloric & 0 & 0 & 0 & 0 & \\
\hline Infrapyloric & 0 & 0 & 1 & 0 & \\
\hline LN along left gastric artery & $2 / 12(16.7 \%)$ & $1 / 6(16.7 \%)$ & $5 / 27(18.5 \%)$ & $7 / 47(14.9 \%)$ & 0.983 \\
\hline LN at Celiac trunk & $0 / 6$ & $0 / 3$ & $1 / 19(5.3 \%)$ & 2/24 (8.3\%) & 0.837 \\
\hline LN along hepatic artery & $0 / 3$ & $0 / 1$ & 3/19 (15.8\%) & $1 / 27(3.7 \%)$ & 0.459 \\
\hline LN along splenic artery & $0 / 2$ & $1 / 3(33.3 \%)$ & $2 / 22(9.1 \%)$ & $1 / 23(4.3 \%)$ & 0.356 \\
\hline LN at splenic hilum & - & - & $3 / 17(17.6 \%)$ & 0/9 & 0.262 \\
\hline
\end{tabular}

* $\mathrm{P}<0.05$; ${ }^{*} \mathrm{P}<0.01$.

${ }^{+}$Number of the patients with nodal metastasis/number of the patients underwet lymph node dissection (\%).

₹ Lower thoracic paraesophageal, diaphragmatic and posterior mediastinal lymph node.

LN Lymph node.

lymph nodes was $37.2 \pm 28.0$ (SD) in each patient. Fortyfive $(48.9 \%)$ of 92 patients had lymph node metastases (pN1-3). Thirty-six (39.1\%), 19 (20.7\%), 17 (18.5\%) and $20(21.7 \%)$ patients were pathologically staged I, II, III and IV, respectively. Forty-nine patients (53.3\%) had preoperative chemotherapy.

Comparison of clinicopathological characteristics among type $\mathrm{E}(\mathrm{SQ}), \mathrm{E}(\mathrm{AD})$, Ge and $\mathrm{G}$ tumor group are summarized in Table 2. There were significant differences in extent of surgical resection, pathological tumor size, main histological type, depth of tumor invasion (pT category), lymph node metastasis ( $\mathrm{pN}$ category), distant metastasis (pM category) and TNM tumor stage. Histologically, 26 (96.3\%) of 27 type Ge tumor and all 47 type $\mathrm{G}$ tumors were adenocarcinoma. Patients with Type G tumors tended to have earlier stage diseases than the other tumor groups.

Incidence of lymph node metastases were summarized in Table 3. Seven (58.3\%) of 12 type E (SQ) tumors, 3 (50.0\%) of 6 type E (AD) tumors, $19(70.4 \%)$ of 27 type
Ge tumors and 14 (29.8\%) of 47 type $G$ tumors had lymph nodes metastases $(P=0.003)$. Although incidence of nodal metastasis in pT1 tumor was significantly lower in the type $G$ tumor group than the other type tumor groups, there was no significant difference in pT2, pT3 and pT4 tumors among 4 tumor groups. With regard to lymph node location, no nodal metastasis in the cervical and mediastinal lymph nodes was seen in the type G tumor group. Although nodal metastases in perigastric lymph nodes were seen in all tumor types, only one nodal metastasis in intra-abdominal lymph nodes, except for perigastric lymph nodes, was recognized in type E tumor group. Nodal metastasis at the splenic hilum was seen in only in the Ge tumor group. As a result, incidence rates for nodal metastasis in cervical, mediastinal, and perigastric lymph nodes differed among 4 patients groups.

Clinicopathological characteristics and clinical courses of seven patients with cervical or mediastinal lymph node metastasis were summarized in Table 4. The 
Table 4 Clinicopathological findings of patients with cervical and mediastinal lymph node metastasis

\begin{tabular}{|c|c|c|c|c|c|c|c|c|c|c|c|c|c|c|c|}
\hline Case & $\begin{array}{l}\text { Tumor } \\
\text { type }\end{array}$ & $\begin{array}{l}\text { Cervical } \\
\text { LN }\end{array}$ & $\begin{array}{l}\text { Mediastinal } \\
\text { LN }\end{array}$ & Age & Sex & $\begin{array}{l}\text { Tumor size } \\
(\mathrm{mm})\end{array}$ & $\underset{+}{\text { Distance }}$ & $\begin{array}{l}\text { Macroscopic } \\
\text { type }\end{array}$ & $\begin{array}{l}\text { Histological } \\
\text { type }\end{array}$ & pT & $\mathrm{pN}$ & $\mathrm{pM}$ & Stage & $\begin{array}{l}\text { Initial recurrence } \\
\text { site }\end{array}$ & Status \\
\hline 1 & $\mathrm{E}(\mathrm{SQ})$ & SC & - & 64 & M & 50 & 65 & Type 0 & SQ (por) & T3 & N3 & MO & $\| I C$ & LN, It. adrenal grand & Deceased \\
\hline 2 & $\mathrm{E}(\mathrm{SQ})$ & SC & LTP & 57 & M & 87 & 69 & Type 0 & SQ (por) & $\mathrm{T} 1$ & N2 & M1 & IV & LN & Deceased \\
\hline 3 & $\mathrm{E}(\mathrm{SQ})$ & - & EH & 72 & M & 25 & 40 & Type 2 & SQ (mod) & T3 & $\mathrm{N} 1$ & MO & $\| I I$ & LN & Deceased \\
\hline 4 & $E(A D)$ & - & $\mathrm{EH}$ & 73 & $\mathrm{~F}$ & 110 & 100 & Type 0 & $A D$ (por) & $\mathrm{T} 2$ & $\mathrm{~N} 1$ & MO & $\| B$ & Peritoneum & Deceased \\
\hline 5 & $E(A D)$ & - & LTP, ID & 62 & M & 45 & 55 & Type 2 & $A D(\bmod )$ & T3 & $\mathrm{N} 1$ & MO & $\| I I A$ & LN & Deceased \\
\hline 6 & Ge & - & LTP & 68 & M & 80 & 30 & Type 1 & AD (mod) & T3 & N3 & MO & IIIC & & $\begin{array}{l}\text { Deceased (other } \\
\text { cause) }\end{array}$ \\
\hline 7 & Ge & - & EH & 41 & M & 65 & 25 & Type 3 & $A D$ (por) & T3 & N3 & M1 & IV & LN & Alive with relapse \\
\hline
\end{tabular}

${ }^{\dagger}$ Distance between proximal edge of tumor and EGJ in $\mathrm{mm}$.

$A D$ adenocarcinoma, EH Esophageal hiatus, ID Infradiaphragmatic, LTP Lower thoracic paraesophageal, LN Lymph node, mod moderately differentiated. por: poorly differentiated, SC, Supraclavicular, SQ Squamous-cell carcinoma. 


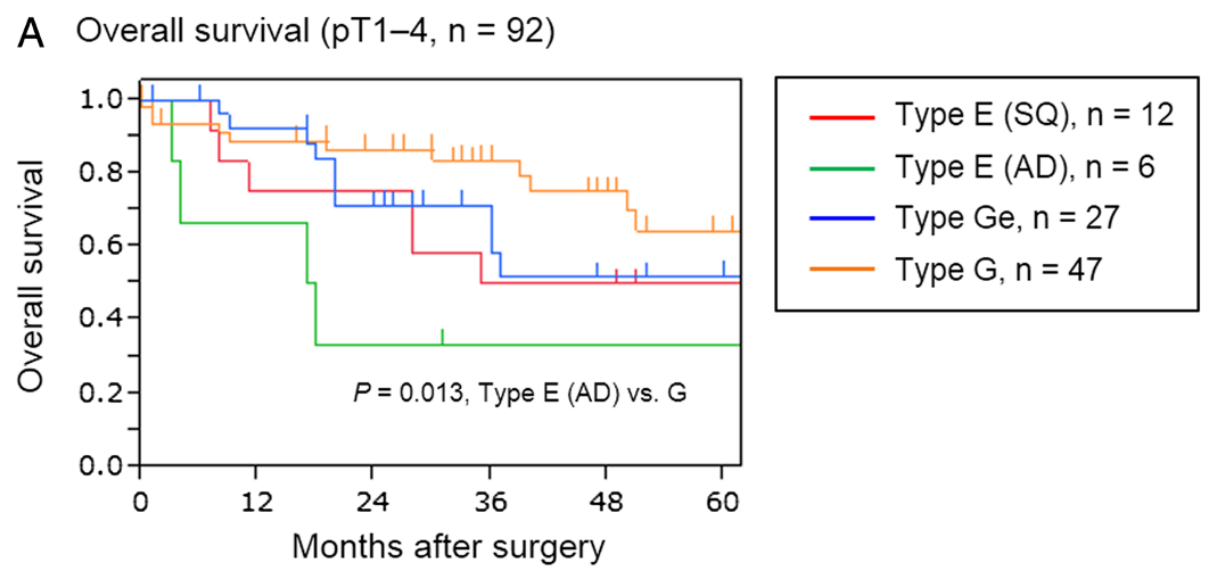

B Overall survival (pT2-4, $n=59)$

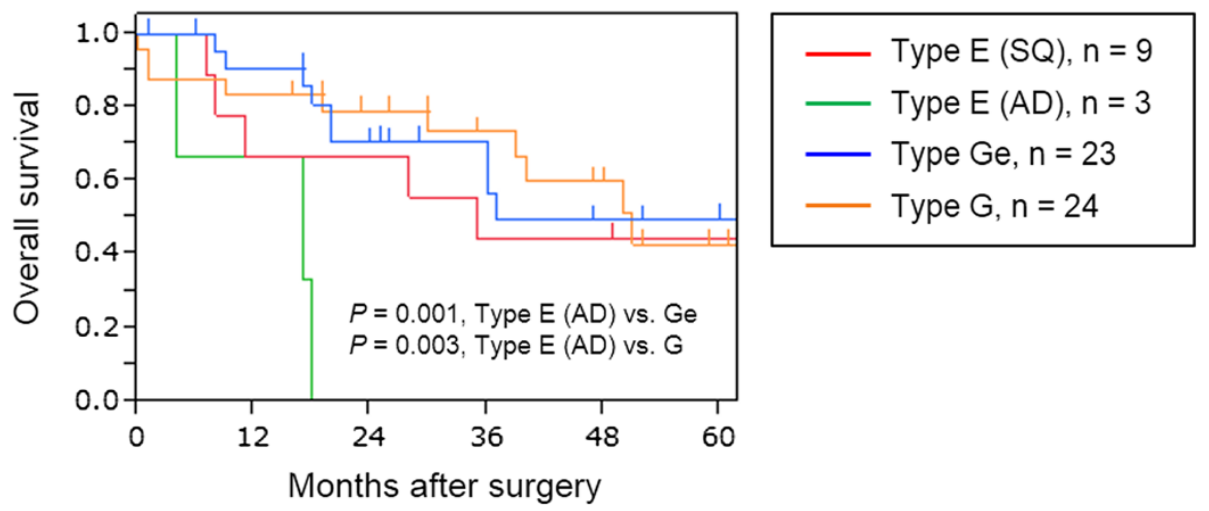

Figure 3 Overall survival of patients. (A) Patients with pT1-4 tumors $(n=92)$. Type $G$ tumor group demonstrated higher overall survival rate compared with type E adenocarcinoma (AD) $(P=0.013)$ tumor group. Although not significantly, the type $\mathrm{G}$ tumor group had a higher survival rate than the type E squamous-cell carcinoma (SQ) $(P=0.366)$ and $\mathrm{Ge}(P=0.850)$ tumor group. (B) Patients with pT2-4 Tumors $(n=59)$. The type E (AD) tumor group demonstrated significantly lower overall survival rate compared with the type $\mathrm{Ge}(P=0.001)$ and type $\mathrm{G}(P=0.003)$ tumor group. The type $E(A D)$ tumor group had a lower survival rate than the type $E(S Q)$ tumor group $(P=0.076)$ although not significantly.

location of mediastinal positive nodes was localized in the lower mediastinal area. Six of 7 patients had disease recurrence and 5 patients were deceased. One patient died of another cause without disease recurrence.

\section{Surgical outcomes}

The 5-year overall survival rate was 56.6\%. Thirty-three patients had disease recurrence. Thirty-four patients deceased. Twenty-five, 1 and 8 patients died of cancer, surgical complication and other causes. Overall survival rates were compared among the patients with type $\mathrm{E}$ (SQ), E (AD), G and Ge tumors. In patients with pT1-4 tumors, the type G tumor group (overall 5-year survival rate was $64.4 \%$ ) demonstrated higher overall survival rate compared with type $\mathrm{E}(\mathrm{AD})$ (overall 5-year survival rate was $33.3 \%)(P=0.013)$ tumor group. Although not significantly, the type $\mathrm{G}$ tumor group had a higher survival rate than the type $\mathrm{E}(\mathrm{SQ})$ (overall 5-year survival rate was $50.0 \%)(P=0.366)$ and $\mathrm{Ge}$ (overall 5 -year survival rate was $51.9 \%) \quad(P=0.850)$ tumor group
(Figure 3A). Because the type $\mathrm{G}$ tumor group had relatively early-stage disease, survival rates were calculated in patients with pT2-4 tumor. In the pT2-4 group, the type E (AD) tumor group demonstrated significantly lower overall survival rate compared with the type Ge (overall 5-year survival rate was $49.4 \%)(P=0.001)$ and type $\mathrm{G}$ (overall 5-year survival rate was $42.8 \%$ ) $(P=0.003)$ tumor group. The type $\mathrm{E}(\mathrm{AD})$ tumor group had a lower survival rate than the type $E(S Q)$ tumor group (overall 5-year survival rate was $44.4 \%)(P=0.076)$ although not significantly (Figure 3B).

\section{Prognostic factor}

A univariate Cox proportional hazard analysis showed that lymphatic invasion $(P<0.001)$ and venous invasion $(P<0.001)$, depth of tumor invasion (pT category; $P<0.001$ ), lymph node metastasis ( $\mathrm{pN}$ category; $P<0.001$ ), distant metastasis ( $M$ category; $P=0.028$ ) were statistically significant for survival. Sex, age and 
Table 5 Univariate Cox proportional hazards analysis of overall survival

\begin{tabular}{|c|c|c|c|}
\hline Variable & Hazard ratio & $\mathbf{9 5 \%}$ confidence interval & $P$-value \\
\hline \multicolumn{4}{|l|}{ Sex } \\
\hline Male $(n=72)$ & 1.0 & & \\
\hline Female $(n=20)$ & 1.391 & $0.611-2.898$ & 0.412 \\
\hline \multicolumn{4}{|l|}{ Age (years) } \\
\hline$\leq 65(n=38)$ & 1.0 & & \\
\hline$>65(n=54)$ & 1.141 & $0.573-2.351$ & 0.711 \\
\hline \multicolumn{4}{|l|}{ Main histological type } \\
\hline Squamous-cell carcinoma $(n=13)$ & 1.0 & & \\
\hline Adenocarcinoma $(n=79)$ & 0.707 & $0.323-1.769$ & 0.432 \\
\hline \multicolumn{4}{|l|}{ Lymphatic invasion } \\
\hline LO $(n=32)$ & 1.0 & & \\
\hline $\operatorname{L1}(n=60)$ & 7.221 & $2.558-30.22$ & $<0.001^{* *}$ \\
\hline \multicolumn{4}{|l|}{ Venous invasion } \\
\hline V0 $(n=32)$ & 1.0 & & \\
\hline$V 1-2(n=60)$ & 4.772 & $1.872-16.12$ & $<0.001^{* *}$ \\
\hline \multicolumn{4}{|l|}{ Depth of tumor invasion } \\
\hline $\mathrm{pT} 1-2(\mathrm{n}=44)$ & 1.0 & & \\
\hline pT3-4 ( $n=48)$ & 4.521 & $1.993-12.14$ & $<0.001^{* *}$ \\
\hline \multicolumn{4}{|l|}{ Lymph node metastasis } \\
\hline $\mathrm{pNO}(\mathrm{n}=47)$ & 1.0 & & \\
\hline $\mathrm{pN} 1-3(\mathrm{n}=45)$ & 4.597 & $2.096-11.54$ & $<0.001^{* *}$ \\
\hline \multicolumn{4}{|l|}{ Distant metastasis } \\
\hline $\mathrm{MO}(\mathrm{n}=72)$ & 1.0 & & \\
\hline$M 1(n=20)$ & 2.257 & $1.094-4.496$ & $0.028^{*}$ \\
\hline
\end{tabular}

LN Lymph node.

mail histological type were not significantly associated with survival (Table 5). A multivariate Cox proportional hazard analysis that included variables with $P<0.10$ in univariate analysis and tumor type (types E (SQ), E (AD), Ge and G) showed that tumor type was an independent significant prognostic factor (Table 6). Among tumor types, the type E (AD) tumor group demonstrated significantly higher risk in survival than did the type E (SQ) (hazard ratio: 0.224; 95\% confidence interval, $0.062-0.911 ; P=0.038$ ), Ge (hazard ratio: 0.162; 95\% confidence interval, $0.048-0.643 ; P=0.012$ ) and $G$ (hazard ratio: 0.219 ; 95\% confidence interval, 0.069$0.839 ; P=0.029)$ tumor group. In the depth of tumor invasion, pT1-2 tumor demonstrated significantly lower survival risk than did pT3-4 (hazard ratio: 2.937; 95\% confidence interval, $1.168-8.698 ; P=0.021$ ) tumor. Regarding lymphatic invasion, L1 showed higher survival risk, however there was no significance (hazard ratio: $4.575 ; 95 \%$ confidence interval, $0.940-25.80 ; P=$ 0.060 ). Venous invasion, lymph node metastasis ( $\mathrm{pN}$ category) and distant metastasis ( $\mathrm{M}$ category) were not significant predictors of survival.

\section{Discussion}

The aim of this study was to clarify the clinicopathological characteristics of cancers around the EGJ, and to investigate optimal management. Standard treatment for EGJC is controversial for several reasons. One of them is that the definition of EGJC is not stable. Siewert et al. define EGJC as adenocarcinoma, centered in area between the lowest $5 \mathrm{~cm}$ of the esophagus and the upper $5 \mathrm{~cm}$ of the stomach, and crossing the EGJ [14]. The Japanese Classification of Esophageal Cancer (JCEC) from the Japan Esophageal Society defines EGJC as being within the lower $2 \mathrm{~cm}$ of the esophagus and the upper $2 \mathrm{~cm}$ of the stomach, because of histological evidence of spreading of columnar epithelium-lined lower esophagus [15]. Moreover, AJCC defines EGJ as including squamous-cell carcinoma in the same locations as with Siewert classification [4].

However Siewert classification is widely used, its application is limited for adenocarcinoma. Although EGJC, as defined by the AJCC cancer staging manual, includes squamous-cell carcinoma, it does not categorize any tumor without EGJ invasion as EGJC-as does Siewert 
Table 6 Multivariate Cox proportional hazards analysis of overall survival

\begin{tabular}{|c|c|c|c|}
\hline Variable & Hazard ratio & $95 \%$ confidence interval & P-value \\
\hline \multicolumn{4}{|l|}{ Tumor type } \\
\hline Type E (AD) $(n=6)$ & 1.0 & & \\
\hline Type E (SQ) $(n=12)$ & 0.224 & $0.062-0.911$ & $0.038^{*}$ \\
\hline Type Ge $(n=27)$ & 0.162 & $0.048-0.643$ & $0.012^{*}$ \\
\hline Type G $(n=47)$ & 0.219 & $0.069-0.839$ & $0.029^{*}$ \\
\hline \multicolumn{4}{|l|}{ Lymphatic invasion } \\
\hline $\mathrm{LO}(\mathrm{n}=32)$ & 1.0 & & \\
\hline $\mathrm{L} 1(\mathrm{n}=60)$ & 4.575 & $0.940-25.80$ & 0.060 \\
\hline \multicolumn{4}{|l|}{ Venous invasion } \\
\hline VO $(n=32)$ & 1.0 & & \\
\hline$V 1-2(n=60)$ & 0.966 & $0.196-5.170$ & 0.967 \\
\hline \multicolumn{4}{|l|}{ Depth of tumor invasion } \\
\hline pT1-2 $(n=44)$ & 1.0 & & \\
\hline pT3-4 $(n=48)$ & 2.937 & $1.168-8.698$ & $0.021^{*}$ \\
\hline \multicolumn{4}{|l|}{ Lymph node metastasis } \\
\hline $\mathrm{pNO}(\mathrm{n}=47)$ & 1.0 & & \\
\hline $\mathrm{pN} 1-3(\mathrm{n}=45)$ & 1.460 & $0.463-5.607$ & 0.537 \\
\hline \multicolumn{4}{|l|}{ Distant metastasis } \\
\hline $\mathrm{MO}(\mathrm{n}=72)$ & 1.0 & & \\
\hline M1 $(n=20)$ & 1.097 & $0.428-2.794$ & 0.846 \\
\hline
\end{tabular}

classification. Although it estimates prognosis well using different staging systems for squamous-cell carcinoma and adenocarcinoma, this method may be too complex for clinicians; whereas the JCEC system, which treats most limited tumors as EGJC, is more precise.

Because of the unstable definition of EGJCs, clinicopathological characters and treatment strategies have not been unified. Siewert et al. argued that complete surgical resection and lymph node metastasis were independent prognostic factors in type II adenocarcinoma, and subtotal esophagectomy had less survival effectiveness for the patients with type II adenocarcinoma [5]. Hasegawa et al. reported that about $40 \%, 60 \%$ and $90 \%$ of patients with type I, II and III tumors, respectively, had lymph node metastases, and recommended complete resection for improving survival [16]. Schiesser et al. reported that subtotal esophagectomy and extended total gastrectomy should be performed for type I and type II-III tumor [17]. With regard to surgical approach, Sasako et al. showed that the left thoracoabdominal approach did not improve survival after the abdominal-transhiatal approach and leads to increased morbidity in patients with cancer of the cardia or subcardia [18]. Kakeji et al. reported that esophagectomy with mediastinal and abdominal lymphadenectomy was adequate for squamous-cell carcinoma, and that extended total gastrectomy with lower mediastinal and abdominal lymphadenectomy was suitable for adenocarcinoma [19]. Carboni et al. maintained effects of extended gastrectomy by an abdominal-trans-hiatal approach for EGJC [20]. Conversely, Chau et al. reported that performance status, liver metastasis, peritoneal metastasis and alkaline phosphatase were independent prognostic factors in patients with locally advanced and metastatic EGJC, and that prognoses of patients with recurrent disease were no better than those without surgery [21].

We studied any tumor centered in area between the lowest $5 \mathrm{~cm}$ of the esophagus and the upper $5 \mathrm{~cm}$ of the stomach, regardless of histological type and EGJ invasion, and simply categorized them in 4 groups including type E (SQ), E (AD), Ge and G.

Whereas type $E(S Q), E(A D)$ and Ge tumors in this study are categorized as esophageal cancer by AJCC/ UICC criteria, these tumor groups show differences in clinicopathological characteristics. In lymph node metastasis, approximately 60\%, 50\%, $70 \%$ and $30 \%$ of the patients with type E (SQ), E (AD), Ge and G tumors respectively had lymph node metastases in this study. Cervical lymph node metastases were recognized in only type E (SQ) tumor group. Because type E (AD) tumor was based on columnar epithelium, its histological behavior was thought to be similar to cardiac adenocarcinoma; however, type E (AD) tumor showed a nodal metastatic spreading pattern similar to that of type Ge 
tumor in this study. Although it seems reasonable to unite type $\mathrm{E}(\mathrm{AD})$ and Ge tumors as a group on the basis of lymphadenectomy extent, the patients with type E (AD) tumor showed significantly lower survival rates than other type tumor groups. Although not significantly, patients with type E (AD) tumor had higher incidence of nodal metastasis at mediastinal lymph node than did patients in tumor groups, and all mediastinal positive nodes existed in lower mediastinal area. Thus, subtotal esophagectomy is not necessary for type $E$ (AD) and Ge tumor, if complete tumor resection can be achieved. Because no cervical or mediastinal lymph node metastasis was recognized in the type G tumor group, we should not perform subtotal esophagectomy for type $\mathrm{G}$ tumor. In multivariate analysys, tumor type (type $\mathrm{E}$ (AD)) was an independent risk factor for survival of the patients with EGJC in this study. The prognosis of cervical or mediastinal node positive patients was poor. Because survival benefit by cervical and mediastinal lymphadenectomy for the node positive patients with EGJC is limited, we should carefully perform subtotal esophagectomy, and cervical and mediastinal lymphadenectomy for EGJC patients. Therefore, extended gastrectomy with or without lower esophagectomy, according to tumor location, and lower mediastinal and abdominal lymphadenectomy is thought to be adequate for patients with EGJC, including type E (SQ) tumor.

Although lymphatic invasion, venous invasion, depth of tumor invasion ( $\mathrm{T}$ category), lymph node metastasis ( $\mathrm{N}$ category) and distant metastasis ( $\mathrm{M}$ category) were significantly prognostic factors in the univariate analysis, tumor type (types E (SQ), E (AD), Ge and G) and depth of tumor invasion (pT3-4 tumor) were significant in the multivariate analysis in this study. It was reported that complete surgical resection and lymph node metastasis were independent prognostic factors in type II adenocarcinoma [5]. We believe that the lack of a significant difference between the prognosis and lymph node metastasis can be explained by limitations of this study such as the small sample size. Distant metastasis ( $M$ category) was not significantly prognostic factor in the multivariate analysis in study. AJCC/UICC TNM staging system for esophageal cancer defines nodal metastasis along lesser curvature as distant metastasis, although lymph node along lesser curvature is one of the main regional lymph nodes of gastric cancer. Because majority of the patient with M1 disease had no hematogenous metastasis in this study, there was a possibility that distant metastasis was not significant for prognosis in this study.

Reim et al. reported that chemotherapy to be more efficacious for EGJC than for distal gastric cancer [22]. The treatment efficacy of chemotherapy before or after surgery is unclear in this small scale retrospective cohort study. To clarify optimal treatment strategy for EGJC, we should confirm the results in this study using a large scale prospective study.

\section{Conclusions}

Patients with type E (AD) and Ge tumor had no cervical lymph node metastasis, and those with type $G$ tumor had no nodal metastasis at cervical and mediastinal lymph node. The incidence of mediastinal lymph node metastasis of type E (AD) tumor group was higher than type Ge tumor group, and survival rate of the patients with type Ge tumor is significantly higher than those with type E (AD) tumor. Therefore we should distinguish type Ge tumor from type E (AD) tumor. Based on our findings from a retrospective analysis in this cohort study, we suggest performing extended gastrectomy with or without lower esophagectomy, according to tumor location, and lower mediastinal and abdominal lymphadenectomy for EGJC.

\section{Competing interests}

The authors declare that they have no competing interests.

\section{Authors' contributions}

HI (Hiroaki Ito)* conceived and designed the study, collected clinical data, and performed the statistical analysis and interpretation of data. HI (Haruhiro Inoue) participated in the study design and performed interpretation of data. NO, HS, MS, SM, YT and HK collected clinical data. SK participated in the study design and coordination. All authors read and approved the final manuscript.

\section{Acknowledgements}

We are extremely grateful to all the patients and to the clinical staff who cared for these patients. We also are thankful to Dr. Shigeharu Hamatani for his reliable pathological diagnoses.

Received: 9 December 2012 Accepted: 4 January 2013 Published: 7 January 2013

\section{References}

1. World Health Organization. International Agency for Research on Cancer: GLOBOCAN 2008. Cancer Incidence and Mortality World Wide. 2008 [http://globocan.iarc.fr/]

2. Pohl H, Welch HG: The role of overdiagnosis and reclassification in the marked increase of esophageal adenocarcinoma incidence. J Nat Cancer Inst 2005, 97:142-146.

3. Lu YK, Li YM, Gu YZ: Cancer of esophagus and esophagogastric junction: analysis of results of 1,025 resections after 5 to 20 years. Ann Thoracic Surg 1987, 43:176-181.

4. Siewert JR, Feith M, Stein HJ: Biologic and clinical variations of adenocarcinoma at the esophago-gastric junction: relevance of a topographic-anatomic subclassification. J Surg Oncol 2005, 90:139-146.

5. Siewert JR, Stein HJ, Feith M: Adenocarcinoma of the esophago-gastric junction. Scand J Surg 2006, 95:260-269.

6. Edge SB, Byrd DR, Compton CC, et al (Eds): AJCC Cancer Staging Manual. 7th edition. New York: Springer; 2009.

7. Sobin LH, Gospodarowicz MK, Wittekind C: TNM Classification of Malignant Tumors. 7th edition. Oxford: Wiley-Blackwell; 2010.

8. Berger B, Stahlberg K, Lemminger A, Bleif M, Belka C, Bamberg M: Impact of radiotherapy, chemotherapy and surgery in multimodal treatment of locally advanced esophageal cancer. Oncol 2011, 81:387-394.

9. Stahl M: Is there any role for surgery in the multidisciplinary treatment of esophageal cancer? Ann Oncol 2010, 21:283-285.

10. Nakajima T, Nishi M, Kajitani T: Improvement in treatment results of gastric cancer with surgery and chemotherapy: experience of 9,700 
cases in the Cancer Institute Hospital. Tokyo. Sem Surg Oncol 1991, 7:365-372.

11. Peeters KC, van de Velde CJ: Improving treatment outcome for gastric cancer: the role of surgery and adjuvant therapy. J Clinical Oncol 2003, 21:272-273.

12. Diazde Liano A, Yarnoz C, Artieda C, Aguilar R, Viana S, Artajona A, Ortiz H: Results of R0 surgery with D2 lymphadenectomy for the treatment of localised gastric cancer. Clin Translat Oncol 2009, 11:178-182.

13. Siewert JR, Stein HJ, Sendler A, Fink U: Surgical resection for cancer of the cardia. Sem Surg Oncol 1999, 17:125-131.

14. Siewert JR, Stein HJ: Classification of adenocarcinoma of the oesophagogastric junction. British J Surg 1998, 85:1457-1459.

15. Japan Esophageal Society: Japanese Classification of Esophageal Cancer. 10th edition: part I. Esophagus 2009, 6:1-25.

16. Hasegawa S, Yoshikawa T, Cho H, Tsuburaya A, Kobayashi O: Is adenocarcinoma of the esophagogastric junction different between Japan and western countries? The incidence and clinicopathological features at a Japanese high-volume cancer center. World J Surg 2009, 33:95-103.

17. Schiesser M, Schneider PM: Surgical strategies for adenocarcinoma of the esophagogastric junction. Recent Results Cancer Res 2010, 182:93-106.

18. Sasako M, Sano T, Yamamoto S, Sairenji M, Arai K, Kinoshita T, Nashimoto A, Hiratsuka M: Left thoracoabdominal approach versus abdominaltranshiatal approach for gastric cancer of the cardia or subcardia: a randomised controlled trial. Lancet Oncol 2006, 7(8):644-651.

19. Kakeji Y, Yamamoto M, Ito S, Sugiyama M, Egashira A, Saeki H, Morita M, Sakaguchi Y, Toh Y, Maehara Y: Lymph node metastasis from cancer of the esophagogastric junction, and determination of the appropriate nodal dissection. Surg Today 2012, 42:351-358.

20. Carboni F, Lorusso R, Santoro R, Lepiane P, Mancini P, Sperduti I, Santoro E: Adenocarcinoma of the esophagogastric junction: the role of abdominal-transhiatal resection. Ann Surg Oncol 2009, 16:304-310.

21. Chau I, Norman AR, Cunningham D, Waters JS, Oates J, Ross PJ: Multivariate prognostic factor analysis in locally advanced and metastatic esophagogastric cancer-pooled analysis from three multicenter, randomized, controlled trials using individual patient data. J Clin Oncol 2004, 22:2395-2403.

22. Reim D, Gertler R, Novotny A, Becker K, Ebert M, Dobritz M, Langer R, Hoefler $\mathrm{H}$, Friess $\mathrm{H}$, et al: Adenocarcinomas of the esophagogastric junction are more likely to respond to preoperative chemotherapy than distal gastric cancer. Ann Surg Oncol 2012, 19:2108-2118.

doi:10.1186/1756-9966-32-2

Cite this article as: Ito et al:: Clinicopathological characteristics and optimal management for esophagogastric junctional cancer; a single center retrospective cohort study. Journal of Experimental \& Clinical Cancer Research 2013 32:2.

\section{Submit your next manuscript to BioMed Central and take full advantage of:}

- Convenient online submission

- Thorough peer review

- No space constraints or color figure charges

- Immediate publication on acceptance

- Inclusion in PubMed, CAS, Scopus and Google Scholar

- Research which is freely available for redistribution

Submit your manuscript at www.biomedcentral.com/submit 